\title{
Psychometric Properties of the Physical Self-perception Profile: Short Clinical Version in Geriatric Populations
}

\author{
José Pedro Ferreira', Maria Helena Cruz ${ }^{1}$, Tiago Ferreira Salgueiro ${ }^{1}$, \\ and Kenneth Richard Fox ${ }^{2}$
}

${ }^{1}$ University of Coimbra, Portugal; ${ }^{2}$ University of Bristol, United Kingdom

\begin{abstract}
The short clinical version of the Physical Self-Perception Profile - (CPSPP) was constructed to measure selfperceptions in the physical domain in older people and patients in clinical and rehabilitation settings. It is made up of subscales to assess perceptions of physical function, physical health, strength, sports competence, body attractiveness and also overall physical self-worth (PSW). Using confirmatory factor analysis, the present study tested the factorial validity of CPSPP, with 1002 Portuguese participants aged 65 or more $(74.39 \pm 7.11)$. This included 501 males $(74.26 \pm 7.08)$ and 501 females $(74.52 \pm 7.15)$ from private and social security institutions or who were living alone but attending senior daily care centres in clinical and rehabilitation settings. Cronbach Alpha values for subscales ranged from .64-.80, showing adequate to very good internal consistency. Linear regression results showed that the Function subscale alone was able to explain $62.2 \%$ of the total variance of PSW in males and $43.3 \%$ in females. Together, Function, Body and Strength subscales were able to explain $73.7 \%$ of the total PSW variance in males and $60.1 \%$ in females. In confirmatory factor analysis, a model of five correlated latent variables showed a better goodness of fit for female than for male participants. However the goodness of fit obtained for the total sample was satisfactory with NFI $=.89, \mathrm{IFI}=.90, \mathrm{CFI}=.90$ and RMSEA $=.08$. Results support the future use of the instrument for assessment of physical self-perceptions with this population and may be particularly useful in rehabilitation and exercise therapy settings.
\end{abstract}

Keywords: physical self, confirmatory factor analysis, older people

\section{Introduction}

Mental health is a state of well-being in which every individual realizes his or her own potential, can cope with the normal stresses of life, can work productively and fruitfully, and is able to make a contribution to her or his community (World Health Organisation, 2014). Self-esteem is seen as a key component of mental health through its role as a buffer against the impact of negative life influences (Mann, Hosman, Schaalma, \& de Vries, 2004). Self-esteem is an outcome of interactions and perceptions in many different life domains such as work, social relationships, and spirituality. In recent decades the physical self has emerged as a key component of identity and the self-esteem system because the body, through its appearance, attributes and abilities provides the substantive interface between the individual and the world (Fox, 1998). Physical self-perceptions have also been directly related to indicators of emotional adjustment, independent of self-esteem (Sonstroem \& Potts, 1996), and emerged as important indicators of change as a result of involvement in physical activity, exercise, and sport, both in adults (Spence \& Poon, 1997) and in youth (Babic et al., 2014).

The physical Self by self and positive levels of mental health and well-being are important across all ages but they remain relevant in later life. Sources of well-being for older adults may be dependent on cultural factors. In some cultures, reaching old age might be accompanied by high social status and respect. For others, it may be dominated by factors such as a decline in physical and cognitive function, loss of independence, less physical activity and engagement with friends and community, perceived reduced role in life (Manthorpe \& Iliffe, 2009). Understanding how older adults perceive their physical selves is therefore important. In particular, delineation and measurement of the components of the physical self can help to inform the targeting of interventions designed to influence broader elements of mental health in older adults.

The late nineteen eighties and early nineties saw the development of new research instruments to assess 
the physical self and determine its place in the selfesteem systems of different populations (Fox, 2000). Instruments such as the Physical Self-Perception Profile (PSPP) (Fox \& Corbin, 1989) and the Physical Self-Description Questionnaire (PSDQ) (Marsh, Richards, Johnson, Roche, \& Tremayne, 1994) revealed excellent psychometric properties in the assessment of different elements of the physical self with adults and young people and these instruments have been widely used in descriptive and intervention research, particularly focusing on physical activity and sport.

Several studies have used the PSPP to assess physical self-perceptions in older adults (Gothe et al., 2011; Opdenacker, Delecluse, \& Boen, 2009; Semerjian \& Stephens, 2007; Sonstroem, Speliotis, \& Fava, 1992). Sonstroem, Speliotis and Fava (1992) suggested that the dimensions of physical self-perceptions may be different for older adults. Recently, more questions have been raised about the adequacy of some of these subdomains to be used with older people (Ferreira, Teixeira, Massart, \& Filaire, 2013), supporting Sonstroem's et al. (1992) concern.

Fox, Stathi, Mckenna and Davis (2007) reported the use of a new version of the PSPP. It was based on an unpublished study by Chase (1991) who conducted qualitative research to identify the salient content of physical self-perceptions in older adults and further pilot studies undertaken by Fox and colleagues (2007).The result was an 18-item (6 subscales) clinical version of the Physical Self-Perception Profile (CPSPP). Fox et al. (2007) reported good internal validity, however, limited information was provided about its structure, validity and reliability. In addition, Ferreira, Fox, Cruz, and Salgueiro (2008) published a preliminarily analysis of the validity and reliability of a Portuguese version of the CPSPP with a small sample of Portuguese older adults and found some evidence of psychometric weakness and need of adjustment before a widespread use in older Portuguese populations could be recommended.

The purpose of the present study, following on from the initial analyses in 2008, was to further develop the Portuguese language version and assess its internal validity and reliability with a larger sample of old Portuguese male and female individuals aged 65 or more, many of whom had health and mobility problems and were regularly attending clinical and rehabilitation settings (hospitals, therapy and rehabilitation services or nursing homes).

\section{Method}

\section{Participants}

The CPSPP was administered to a sample of independent and cognitively healthy older adults aged 65 or over and living in one of four different districts in central Portugal (Coimbra, Leiria, Aveiro and Viseu) and who were regularly attending clinical and rehabilitation settings (hospitals, therapy and rehabilitation services or nursing homes). Participants with neurodegenerative diseases were excluded from the study as they may influence the individual's cognitive ability to fill in the questionnaire and answer the questions. In order to reflect the socio-economic diversity of the older population in this geographic area, participants were recruited equally from both private and public social security institutions, senior daily care centres and nursing homes in both rural and urban settings. Access to those private versus public institutions is a relevant indicator of personal income and economic status in Portuguese older adults. Participants were all volunteers and no incentives were provided.

\section{Measurements}

The Physical Self Perception-Profile - short clinical version (CPSPP) (Fox et al., 2007) is a self-report multidimensional instrument designed to provide a summary of self-evaluations in the physical domain in clinical and rehabilitation settings and in elderly groups by older groups. The CPSPP consists of five three-item subscales assessing the following subdomains: Physical function (Function), Physical health (Health), Sport competence (Sport), Body attractiveness (Body) and Physical strength (Strength), and an additional three-item subscale that assesses overall Physical SelfWorth (PSW). Answers to all the items are displayed in a structured alternative format (previously shown to eliminate social desirability bias) with a possible range of scores from 3 to 12. Preliminary psychometric properties of this English version reported by Fox et al. (2007) showed Cronbach Alpha internal consistency coefficients ranging from acceptable to good (.62 to .81 ) in all the CPSPP subdomains.

The CPSPP English-Portuguese translation process was previously accomplished by Ferreira et al. (2008) and followed the guidelines suggested by Vallerand (1989). This process included the preparation of four different preliminary versions followed by a four-experts-discussion group aiming to achieve full consensus for the lexical and cultural equivalence of 
the developmental version. A back translation of this version was performed by two experts in English language with knowledge of the Portuguese language in order to identify any discrepancies between the translation sense and the original questionnaire. This previous study revealed some evidence of inadequacies in some of the items and subscales. For example, although the Function, Health and Body subscales showed good internal consistency with Cronbach Alpha coefficients of .76, .63 and .70 for females and $.77, .77$ and .70 for males, the Sport and Strength subscales presented lower internal consistency values of .50 and .45 for females and .48 and .52 for males. Therefore, further adjustments were made before administration in the current study by a group of three experts who reviewed the notes, analysed and discussed the major difficulties identified in 2008 , reviewed the translation of some of the items and introduced minor lexical changes.

The Rosenberg Self-Esteem Scale (RSES) (Rosenberg, 1965) is a uni-dimensional ten-item instrument using a four-point Likert Scale to which participants respond from strongly agree to strongly disagree. Global Self-esteem is represented by the sum of all item scores providing a possible range of 10 to 40 with higher scores indicating higher self-esteem (GSE). RSES has been validated in many different studies (Hagborg, 1993; Rosenberg, 1965; Silber \& Tippett, 1965) and was translated into Portuguese language (RSESp) by Marques et al. (1991) and reviewed by Ferreira and Meek (2001). Silber and Tippett (1965) reported a test-retest reliability value of .85 and Ferreira and Fox (2007) reported a test-retest reliability coefficient of $r=.75$ over a two-week lapse period.

\section{Procedures}

Participants were recruited through verbal announcements at private and social security institutions and senior daily care centres. The purpose of the study was explained and interested participants were asked to complete an informed consent form. Volunteers were then helped individually by a research assistant to complete the assessment instrument. In some cases where participants had difficulty, individual items were read and/or explained. The average time for administration was 30 minutes. Test-retest stability for CPSPP was assessed through a re-administration of the instrument to a randomly sampled group $(n=30)$ after a lapse period of 3 weeks. This was a subgroup of the original sample where everyone had an equal chance of being selected to take part in the second administration (Bryman, 2001).

\section{Statistical analysis}

The full range of descriptive statistics, including mean, standard deviation, skewness, kurtosis, was calculated for all CPSPP subdomains by gender and factor solutions were compared with those previously obtained by Ferreira et al. (2008). Gender differences have consistently emerged across studies that have investigated self-perceptions (Fox, 2000). Tests of univariate normality were used to examine the skewness and kurtosis levels in the sample data. Internal consistency was measured using Cronbach Alpha coefficient values (Cronbach, 1951) and test-retest stability was measured using Pearson's product-moment $r$. Linear regression (stepwise method) was used to assess the percentage of the total variance in physical self-worth explained by each subdomain subscale score. Comparison between gender groups was accomplished using independent T-test. Statistical package for Social Sciences (SPSS) version 22.0 was used to carry out all the analyses and significance was set at $p<0.05$.

Additionally, IBM SPSS AMOS version 22.0 was used to perform confirmatory factor analysis (CFA) using robust conditions to test the goodness-of-fit of the original CPSPP structure suggested by Fox et al. (2007) with all participants $(N=1002)$ and with both male $(n=501)$ and female $(n=501)$ subsamples. The PSW was excluded from first order CFA as it theoretically and empirically functions as a super-ordinate construct, resulting from weighted combinations of self-perceptions in the different subdomains, as suggested by Fox and Corbin (1989) for the adults PSPP. The hypothesized model is illustrated in Figure 1.

Items were uniquely loaded on hypothesized factors, the variance of each factor was fixed at one to define the scale of the latent factors. Factors were allowed to correlate and measurement errors were not allowed to correlate. The hypothesized model was evaluated using multiple goodness of fit indices (GFIs) as suggested by different authors (Hu \& Bentler, 1999): the Chi-square $\left(\chi^{2}\right)$ test statistic, the Root Mean Square Error of Approximation (RMSEA), the Normed Fit Index (NFI), the Incremental Fit Index (IFI) and the Comparative Fit Index (CFI).

The chi-square test was used to assess the likelihood of the parameters given the data, however, it is extremely sensitive to sample size. Even reasonable models, in large samples, are likely to produce statistically significant chi-square p values (Bentler, 1990; Bentler \& Bonett, 1980; Jöreskog \& Sörbom, 1989). For this reason it is also recommended that the ratio 
of chi-square to the degrees of freedom $\left(\chi^{2} / d f\right)$ (Bryant $\&$ Yarnold, 1995) together with the other fit indices should be reported. When the $\chi^{2} / d f$ is close to zero, the fit of the model is good (Hoelter, 1983) and when it is below 5, the model is considered as acceptable (Schumacker \& Lomax, 2016). Additionally, CFIs cutoff criteria values for RMSEA are $<.05$ good fit and .05-.08 acceptable fit, and for the other CFIs situated above .90 (Bentler \& Bonett, 1980). However, Bentler and Bonett (1980) also stated that models with overall fit indices of less than 90 can usually be improved $(p=.600)$ and this is quite different from the normal attribution that SEMs whose GFIs are less than .90 are generally inadequate (Lance, Butts, \& Michels, 2006). The .90 cutoff indicates well-fitting models and can be applied to a wide range of overall GFIs. However that does not mean that GFIs lower that .90 indicates that the model should be refused. It means that there is scope for improvement.

\section{Results}

Table 1 shows personal and geographic characteristics of the participants involved in the study. The final sample was 501 Portuguese males $(74.26 \pm 7.08)$ and 501 females $(74.52 \pm 7.15)$ from private and public social security institutions, senior daily care centres and nursing homes. All participants were regularly attending a clinical or rehabilitation settings (hospitals, therapy and rehabilitation services or nursing homes). Moreover, $58.5 \%(n=586)$ were from the 65 to 75 years age group and $41.5 \%(n=416)$ were older

Table 1

Gender, age group, marital status and geographic characteristics from participants $(N=1002)$

\begin{tabular}{llcc}
\hline Characteristics & & $\mathrm{N}$ & $\%$ \\
\hline \multirow{2}{*}{ Gender } & Male & 501 & 50.0 \\
& Female & 501 & 50.0 \\
\hline \multirow{2}{*}{ Age group } & 65-75 years & 586 & 58.5 \\
& $>75$ years & 416 & 41.5 \\
\hline \multirow{3}{*}{ Marital status (\%) } & Single & 182 & 18.2 \\
& Married & 463 & 46.2 \\
& Widowed & 42 & 4.2 \\
& Other & 2 & 313 \\
& Aveiro & 251 & 25.05 \\
\hline \multirow{2}{*}{ District } & Viseu & 177 & 17.66 \\
& Coimbra & 237 & 23.65 \\
& Leiria & 337 & 33.64 \\
\hline
\end{tabular}

than 75 years. Furthermore, $46.2 \%$ of the participants were married, $31.2 \%$ widowed, $18.2 \%$ single, $4.2 \%$ divorced and $0.2 \%$ with other status.

Table 2 shows descriptive statistics and internal consistency values from the six CPSPP subdomains and global self-esteem from male, female and total sample groups.

A Shapiro-Wilk's test $(p>0.05)$ (Razali \& Wah, 2011) and a visual inspection of its histograms, normal Q-Q plots and box plots showed that CPSPP subscale values were approximately normally distributed for both male and female groups All skewness and kurtosis values were adequate as they ranged between -1.96 and +1.96 , which is considered as a normal univariate distribution (George \& Mallery, 2010).

The subscale means clustered around 7.0 (possible range 4-12) with standard deviations ranging between 2.2 and 2.7, showing adequate dispersion. The Function and PSW subscales showed the highest mean values for both males $(7.84 \pm 2.71 ; 7.61 \pm 2.47)$, and females $(7.98 \pm 2.61 ; 7.56 \pm 2.44)$. Sport showed the lowest mean value for both males $(7.03 \pm 2.32)$ and females $(6.88 \pm 2.29)$. Function was the only subscale where females presented higher mean values $(7.98 \pm 2.61)$ than males $(7.84 \pm 2.71)$. However, no statistical differences were found between both groups.

Cronbach Alpha coefficients ranged from .65 to .80 , indicating a good level of internal consistency and showing higher values to those reported in previous studies using the same instrument (Ferreira et al., 2008; Fox et al., 2007). Values were comparable for both genders.

In the total sample, Health and Sport subscales showed the lowest total Cronbach Alpha values (.66 and .68, respectively), while Function and PSW subscales showed the highest total Cronbach Alpha values (.78 and .77, respectively). Test-retest stability revealed high Pearson's correlation coefficients ranging from $r=.80$ to $r=.94$ after a 3 weeks lapse period, indicating the capacity of the instrument to reproduce scores, and indicating the stability of the constructs.

In order to investigate the degree to which there is evidence of a two-level hierarchical organization of CPSPP subscales, Figure 1 shows (a) zero order correlation coefficients among the CPSPP subscales and with PSW and GSE, and (b) partial correlation coefficients between the five lower level subdomainsubscales and GSW with the effect of PSW statistically removed.

The PSW subdomain shows that the relationships among the CPSPP subscales are comparable to those 
Table 2

Descriptive statistics and internal consistency values from CPSPP subdomains and GSE from male, female and total sample groups

\begin{tabular}{|c|c|c|c|c|c|c|c|c|c|}
\hline \multirow[b]{2}{*}{ Sub-domains } & \multirow{2}{*}{$\begin{array}{l}\text { Sample } \\
\text { groups }\end{array}$} & \multirow[b]{2}{*}{$N$} & \multirow[b]{2}{*}{$M$} & \multirow[b]{2}{*}{$S D$} & \multirow[b]{2}{*}{ Skewness } & \multirow[b]{2}{*}{ Kurtosis } & \multirow[b]{2}{*}{$p$} & \multicolumn{2}{|c|}{$\alpha$} \\
\hline & & & & & & & & Present study & $\begin{array}{c}\text { Ferreira } \\
\text { et al. }(2008)\end{array}$ \\
\hline \multirow{2}{*}{ Function } & Male & 501 & 7.84 & 2.712 & -.180 & -1.057 & \multirow{2}{*}{.434} & .80 & .77 \\
\hline & Female & 501 & 7.98 & 2.614 & -.138 & -1.101 & & .76 & .76 \\
\hline \multirow{2}{*}{ Health } & Male & 501 & 7.50 & 2.300 & .059 & -.785 & \multirow{2}{*}{.063} & .67 & .77 \\
\hline & Female & 501 & 7.23 & 2.256 & .111 & -.784 & & .65 & .63 \\
\hline \multirow{2}{*}{ Sport } & Male & 501 & 7.03 & 2.315 & .145 & -.799 & \multirow{2}{*}{.317} & .68 & .48 \\
\hline & Female & 501 & 6.88 & 2.292 & .285 & -.641 & & .67 & .50 \\
\hline \multirow{2}{*}{ Body } & Male & 501 & 7.22 & 2.494 & .135 & -.842 & \multirow{2}{*}{.417} & .77 & .70 \\
\hline & Female & 501 & 7.09 & 2.406 & .132 & -.777 & & .75 & .70 \\
\hline \multirow{2}{*}{ Strength } & Male & 501 & 7.21 & 2.459 & .185 & -.795 & \multirow{2}{*}{.486} & .76 & .52 \\
\hline & Female & 501 & 7.11 & 2.345 & .218 & -.710 & & .69 & .45 \\
\hline \multirow{2}{*}{ PSW } & Male & 501 & 7.61 & 2.473 & -.015 & -.857 & \multirow{2}{*}{.719} & .78 & - \\
\hline & Female & 501 & 7.56 & 2.440 & .188 & -1.000 & & .76 & - \\
\hline \multirow{2}{*}{ GSE } & Male & 454 & 25.57 & 4.48 & .042 & .273 & \multirow{2}{*}{.095} & - & - \\
\hline & Female & 415 & 26.06 & 4.12 & .174 & .669 & & - & - \\
\hline
\end{tabular}

Note. Body = Body attractiveness; Function $=$ Physical function; GSE = Global Self-esteem; Health= Physical health; PSW $=$ Physical Self-Worth; Sport = Sport competence; Strength $=$ Physical strength .

reported by Fox and Corbin (1989) in the original study for the validation of the adult PSPP. Zero-order correlation coefficients also showed a moderately strong relationships between PSW and each of the five subdomain scales $(p<.05)$ for both male and female subgroups. The direct relationship between the five subdomains and global self-worth decreases or is in some cases extinguished when the effects of PSW are statistically removed, confirming previous research indicating that PSW does act as an higher order, mediating construct between the five lower order constructs and global self-esteem.

Nevertheless, the relationship between PSW and GSE is not as well defined as in previous studies, especially in males. The PSW correlation with GSW for males is weaker than the direct correlations between all the other subscales and GSE. However, each subscales shows a stronger relationship with PSW than with GSE.

Linear regression analyses performed by gender revealed that Function alone was able to explain
$62.2 \%$ of the total PSW variance in males and $43.3 \%$ in females. Furthermore, three of the five subdomain scales (Function, Body and Strength) were able to explain $73.7 \%$ of the total PSW variance in males and $60.1 \%$ in females.

Figure 2 shows the results of the CPSPP confirmatory factor analysis for the five-factor model tested with the total sample and with male and female subsamples. The ratio of participants to item was 55.57 for the total sample and 27.83 for both male and female subsamples which is well above the generally recommended ratio of 10:1 (Tabachnick \& Fidell, 2007).

Table 3 shows the CPSPP three items five factors structural model goodness of fit indices results for male and female subgroups and for the total sample.

The $\chi^{2}$ values obtained for male (448.85) and female (350.60) subgroups differ significantly from the independence model $(p<.001)$ which assumes that all relationships among measured variables are zero. The NFI, IFI and CFI indices across the different 

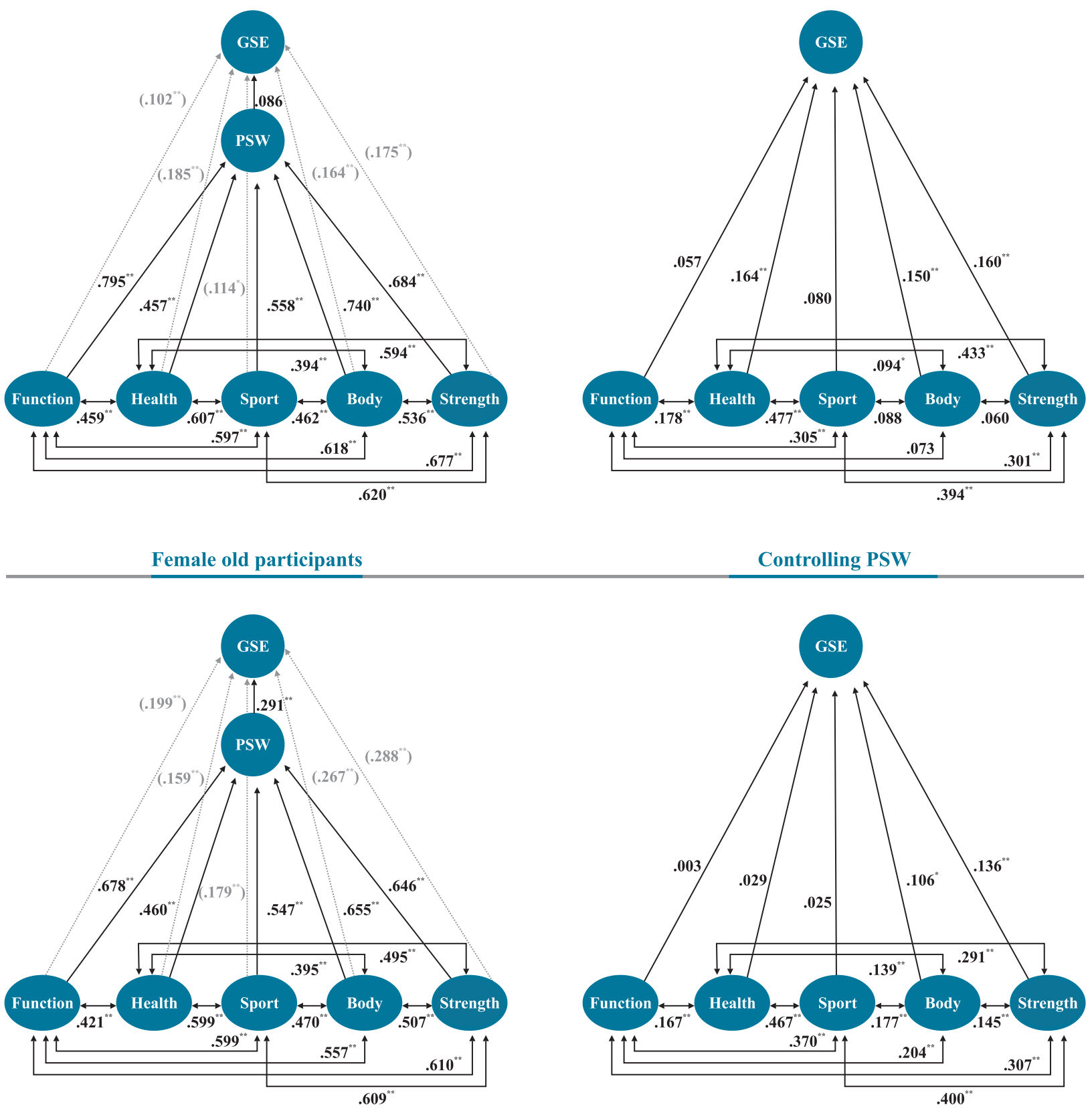

Figure 1. Zero order and partial correlation coefficients from male and female Portuguese old participants. Body $=$ Body attractiveness; Function $=$ Physical function; GSE $=$ Global Self-Esteem; Health $=$ Physical health; PSW $=$ Physical Self-Worth; Sport $=$ Sport competence; Strength $=$ Physical strength .

Table 3

CPSPP structural model goodness of fit indices for male and female subgroups and for the total sample

\begin{tabular}{|c|c|c|c|c|c|c|c|c|}
\hline \multicolumn{2}{|c|}{ Sample groups } & \multirow{2}{*}{$\frac{\chi^{2}}{350.596}$} & \multirow{2}{*}{$\begin{array}{l}d f \\
80\end{array}$} & \multirow{2}{*}{$\frac{\chi^{2} / d f}{4.38}$} & \multirow{2}{*}{$\begin{array}{c}p \text { value } \\
.000\end{array}$} & \multirow{2}{*}{$\begin{array}{c}\text { NFI } \\
.87\end{array}$} & \multirow{2}{*}{$\begin{array}{r}\text { IFI } \\
.90\end{array}$} & \multirow{2}{*}{$\begin{array}{c}\text { CFI } \\
.90\end{array}$} \\
\hline Female & $(n=501)$ & & & & & & & \\
\hline Male & $(n=501)$ & 448.846 & 80 & 5.61 & .000 & .86 & .89 & .89 \\
\hline Total & $(N=1002)$ & 643.724 & 80 & 8.05 & .000 & .89 & .90 & .90 \\
\hline
\end{tabular}

Note. $\quad \mathrm{CFI}=$ Comparative Fit Index; IFI = Incremental Fit Index; NFI = Normed Fit Index. 


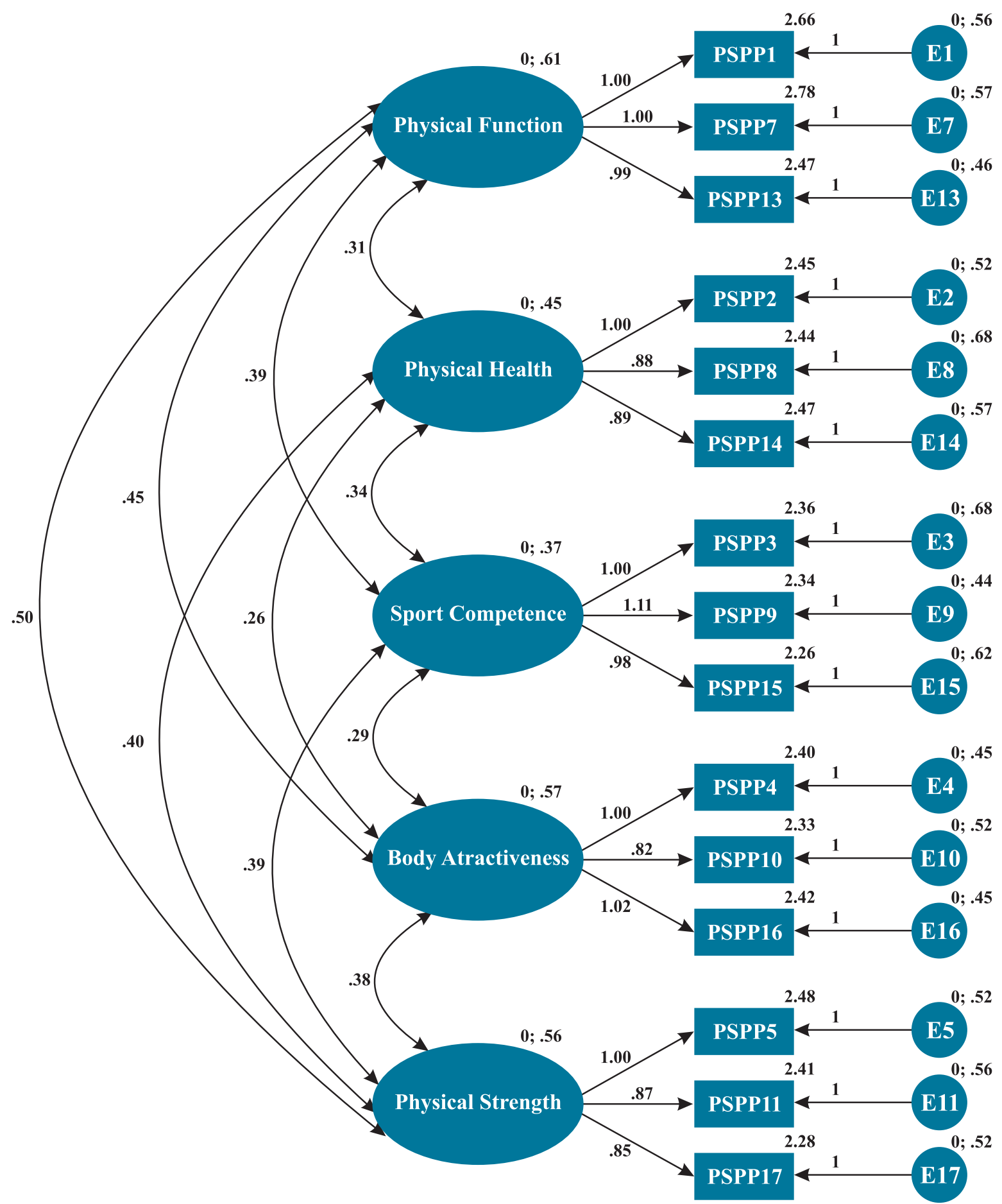

Figure 2. First order CPSPP confirmatory factor analysis three items five-factors model used with the total sample of Portuguese old participants $(N=1002)$.

subgroups were $.86, .89$ and .89 for males and $.87, .90$ and .90 for females. RMSEA was .08 in female and higher than .90 in male samples. The analyzed model of five correlated latent variables showed a better goodness of fit for female than for male participants.
However, the goodness of fit obtained for the majority of the fit indices was satisfactory for the total sample with $\mathrm{NFI}=.89, \mathrm{IFI}=.90, \mathrm{CFI}=.90$ and RMSEA $=.08$. 


\section{Discussion}

The purpose of the present study was to further develop and investigate the psychometric integrity (reliability and dimensionality) of a translated version of the CPSPP, constructed to measure physical self-perceptions in the physical domain with Portuguese older people.

Previous studies (Ferreira et al., 2013; Sonstroem et al., 1992) questioned the sensitivity of the original adult version of the PSPP to assess older people and patients in clinical and rehabilitative settings. Many old people and patients with health problems become concerned about specific aspects of their physical selves and in particular the way they are maintaining physical function.

In this study, the CPSPP was administered to a sample of 1002 elderly participants $(M=74.39$ years) exhibiting a wide range of ages (65 to 94 years of age), with $41.5 \%$ being more than 75 years of age. In addition, the sample was drawn from diverse locations (inland versus seaside, rural versus urban), and different socio-economic and educational levels. Heterogeneity of the validation sample can be seen as a strength of the validation process (Lane, Harwood, Terry, \& Karageorghis, 2004). Results from this study with a large and diverse sample of older Portuguese participants reveal similar and logical patterns, including mean and standard deviations ranges for all subdomains both in male and female subgroups when compared with earlier studies with the CPSPP (Fox et al., 2007; Ferreira et al., 2008). Findings also revealed acceptable to good internal consistency and reliability for all subscales. The internal consistency expressed through the Cronbach Alpha values is considered as acceptable to good (Gliem \& Gliem, 2003) and congruent with previous values reported by Ferreira et al. (2008). All Alpha values were higher than .64 and most values ranged from .75 to .80 revealing a good internal consistency. Temporal stability was very good with $r$ values higher than .80 for all subscales after a 3 weeks period.

Apart from the four traditional PSPP subscales described by Fox and Corbin (1989), the CPSPP assesses two additional subscales - the Physical function (Function) and the Physical health (Health) - developed to assess constructs that are highly relevant to ageing and to those in clinical and rehabilitation settings (Chase, 1991). Function includes perceptions of level of global functionality of the body, ability to perform basic daily life tasks, and confidence in daily life settings where these skills are required. Health includes perceptions of level of physical health, ability to maintain a good level of physical health and confidence in using environments that play a positive role in maintaining a good physical health.

Linear regression analysis revealed the newly introduced Function subscale as the strongest in the model as it was able to explain by itself $62.2 \%$ of the total variance for PSW in males and $43.3 \%$ in females, confirming the earlier concerns of Sonstroem at al. (1992). Function replaced the physical condition subscale in the original PSPP which was more oriented to physical fitness. Function, Body and Strength were able to explain $73.9 \%$ of the total variance for PSW in males and $60.2 \%$ in females. This supports the hierarchical structure of the instrument and the role of PSW as a super-ordinate construct resulting from weighted combinations of self-perceptions in the different subdomains of the physical self.

Furthermore, additional evidence for the hierarchical structure of the instrument was provided by the Function and Health subscales that revealed a positive strong and moderate relationship with PSW respectively, both in male and female subgroups and a positive moderate to strong relationships with all the other CPSPP subdomains. Among all subscales, Sport presented the lowest mean value for both male and females. These results suggest that older people do not consider themselves to be athletic and sporty. Many older Portuguese adults rarely experience the opportunity to formally or informally get involved with regular sport activities over the lifespan (Ferreira et al., 2013).

Moreover, Health showed a positive moderate to strong relationship with Sport and Strength subscales, both in male and female elderly participants. Less positive perceptions of sport and athletic ability or muscle development and physical strength were highly associated with lower levels of perceived ability to maintain a good level of physical health. Additionally, the relationship between Health and Function subscales was also moderate and positive, meaning that individual feelings of functional ability, level of performance and perceived strength capacity are very important for the way Portuguese older people perceive their individual level of physical health and their ability to maintain it positive. Therefore sport and exercise policies for older adults could be very important for the physical well-being of older adults and this might also influence the way they see themselves and their mental welfare. 
Similarly to previous studies with different age groups of the Portuguese population (Ferreira \& Fox, 2007; Ferreira et al., 2008; Ferreira et al. 2013), present results provided further evidence to the fact that Portuguese people do not rely on their physical selves as part of their self-esteem. The relationship between GSE and PSW compared to relationships between GSE and subdomains of PSPP situated lower down in the model was not as strong as described in the review of literature with younger groups (Hayes, Crocker, \& Kowalski, 1999; Lindwall, Aşçi, Palmeira, Fox, \& Hagger, 2011; McAuley, Mihalko, \& Bane, 1997; Sonstroem, 1997). In this particular sample, relationship between PSW and GSE is weak, particularly in males. A possible explanation is that through the aging process, Portuguese older people become less concerned about their body image and about the physical aspects of their body, accepting their physical decline. It is possible that older people are more centred on their mental and social health when compared to their physical selves than younger adults.

Structural equation analysis using CFA revealed goodness of fit indices (GFIs) differences between male and female subgroups. Structural equation models (SEMs) whose GFIs indices exceed .90 indicate a good model fit (Bentler, 1990; Bentler \& Bonett, 1980; Lindwall et al., 2011). The tested model of five correlated latent variables showed better GFIs for female than for male subgroups, however the model tested in the male subgroup showed a good potential level of improvement (Bentler \& Bonett, 1980) and should not be refused. Additionally, the GIFs obtained when the model was tested with the total sample (male and female subgroups) were good, reinforcing the idea that potential increments in the male model are very much possible and desirable. Similar GIFs were reported by Ferreira et al. (2008) in the preliminary validation study.

Furthermore, very similar results were also reported by Fonseca and Fox (2002), Ferreira (2004) and Ferreira and Fox (2007), all using the adults version of the PSPP with Portuguese young and middle-age adults. In all these studies, female groups always presented stronger GFIs than the males, revealing a tendency for more clear feelings about the physical self in female than in male Portuguese individuals, as it is the case of the present study. This results provide solid evidence for the internal structure of the CPSPP with five well defined subscales that are successfully measuring older people's independent but related constructs in the physical self-domain.

\section{Conclusion}

The findings of the present study provide evidence for the psychometric properties of the CPSPP among old people in clinical and rehabilitation environments. In spite of the CFA results showing that the three items five factors model tested revealed a better goodness of fit in females than males, the goodness of fit obtained for the majority of the fit indices was more than adequate for the total sample. This, along with the other psychometric markers for internal consistency and reliability, mean that the instrument can be recommended for further use and development with this particular population.

Further work is needed to assess the role of social factors such as socio-economic status, educational level, and cultural and life experiences in the formulation of physical self-perceptions in older adults and their influences on health attitudes and behaviors.

\section{References}

Babic, M. J., Morgan, P. J., Plotnikoff, R. C., Lonsdale, C., White, R. L., \& Lubans, D. R. (2014). Physical activity and physical self-concept in youth: systematic review and metaanalysis. Sports Medicine, 44(11), 1589-1601.

Bentler, P. M. (1990). Comparative fit indexes in structural models. Psychological bulletin, 107(2), 238.

Bentler, P. M., \& Bonett, D. G. (1980). Significance tests and goodness of fit in the analysis of covariance structures. Psychological Bulletin, 88(3), 588-606. doi:10.1037/0033-2909.88.3.588

Bryman, A. (2001). Social Research Methods. Oxford: Oxford University Press.

Bryant, F. B., \& Yarnold, P. R. (1995). Principal-components analysis and exploratory and confirmatory factor analysis. In L.G. Grimm and P.R. Yarnold (Eds.), Reading and understanding multivariate statistics (pp. 99-136). Washington, DC, US: American Psychological Association, ix, 373 pp.

Chase, L. A. (1991). Physical self-perceptions and activity involvement in the older population. (Doctoral dissertation, Arizona State University, 1991). Dissertation Abstracts International, 52, 2458.

Cronbach, L. J. (1951). Coefficient alpha and the internal structure of tests. Psychometrika, 16, 297-334.

Ferreira, J. (2004). Reflexão sobre que modelo de medida para as autopercepções no domínio físico a partir da versão portuguesa do Physical Self-Perception Profile. In J. Dosil Díaz and D. Garcia Prieto (Eds.), Proceedings of the I Congreso Galego-Português de Psicoloxia da Actividade Física e do Deporte (pp.141-151). Vigo, Spain

Ferreira, J. P., \& Meek, G. A. (2001). Portuguese wheelchair athletes self-perceptions in the physical domain: Preliminary analysis. In M. Dinold and B. Mössenböck (Eds.), Proceedings of the 13th International Symposium, 5th European Congress of Adapted Physical Activity (p. 50). Vienna, Austria. 
Ferreira, J. P., \& Fox, K. R. (2007). An investigation into the structure, reliability and validity of the Physical SelfPerception Profile in non english speaking settings. International Journal of Applied Sport Sciences, 19(1), 25-47.

Ferreira, J. P., Fox, K. R., Cruz, M. H., \& Salgueiro, T. (2008). Preliminary validation with elderly people of the Portuguese short slinical version of the Physical Self-Perception Profile. In Faculty of Human Kinetics (Ed.), Proceedings of the 13th Annual Congress of the European College of Sport Science (pp. 253-254). Estoril, Portugal.

Ferreira, J. P., Teixeira, A. M., Massart, A. G., \& Filaire, E. (2013). Assessing self-esteem and perceived physical competence in elderly using the Physical Self-Perception Profile. European Journal of Adapted Physical Activity, 6(2), 7-18.

Fonseca, A. M., \& Fox, K. R. (2002). Como avaliar o modo como as pessoas se percebem fisicamente? Um olhar sobre a versão portuguesa do Physical Self-Perception Profile. Revista Portuguesa de Ciencias do Desporto, 2, 11-23.

Fox, K. R. (1998). Advances in the measurement of the physical self. In J. L. Duda (Ed.), Advances in Sport and Exercise Psychology Measurement (pp. 295-310). Morgantown: Fitness Information Technology, Inc.

Fox, K. R. (2000). Self-esteem, self-perceptions and exercise. International Journal of Sport Psychology, 31(2), 228-240.

Fox, K. R., \& Corbin, C. B. (1989). The Physical Self-Perception Profile: Development and Preliminary Validation. Journal of Sport and Exercise Psychology, 11, 408-430.

Fox, K. R., Stathi, A., McKenna, J., \& Davis, M. G. (2007). Physical activity and mental well-being in older people participating in the Better Ageing Project. European Journal of Applied Physiology, 100(5), 591-602. doi:10.1007/ s00421-007-0392-0

George, D., \& Mallery, M. (2010). SPSS for Windows Step by Step: A Simple Guide and Reference, 17.0 update (10th ed.). Boston: Pearson.

Gliem, J. A., \& Gliem, R. R. (2003). Calculating, interpreting, and reporting Cronbach's alpha reliability coefficient for likert-type scales. 2003 Midwest Research to Practice Conference in Adult, Continuing, and Community Education, (1992), 82-88. doi:10.1109/PROC.1975.9792

Gothe, N. P., Mullen, S. P., Wójcicki, T. R., Mailey, E. L., White, S. M., Olson, E., ... McAuley, E. (2011). Trajectories of change in self-esteem in older adults: exercise intervention effects. Journal of Behavioral Medicine, 34(4), 298-306. doi:10.1007/s10865-010-9312-6

Hagborg, W. J. (1993). The Rosenberg Self-Esteem scale and Harter's Self-Perception profile for adolescents: a concurrent validity study. Psychology in the Schools, 30(2), 132-136.

Hayes, S., Crocker, P., \& Kowalski, K. (1999). Gender differences in physical self-perceptions, global self-esteem and physical activity: Evaluation of the physical self-perception profile model. Journal of Sport Behavior, 22(1), 1.

Hoelter, J. W. (1983). The analysis of covariance structures goodness-of-fit indices. Sociological Methods \& Research, 11(3), 325-344.

Hu, L., \& Bentler, P. M. (1999). Cutoff criteria for fit indexes in covariance structure analysis: Conventional criteria versus new alternatives. Structural Equation Modeling, 6, 1-55.

Jöreskog, K. G, \& Sörbom, D. (1989). LISREL 7: A Guide to the Program and Applications (2nd ed.). Chicago, IL.: SPSS Inc.
Lance, C. E., Butts, M. B., \& Michels, L. C. (2006). The Sources of Four Commonly Reported Cutoff Criteria: What Did They Really Say? Organizational Research Methods, 9(2), 202-220. doi:10.1177/1094428105284919

Lane, A. M., Harwood, C., Terry, P. C., \& Karageorghis, C. I. (2004). Confirmatory factor analysis of the Test of Performance Strategies (TOPS) among adolescent athletes. Journal of Sports Sciences, 22(9), 803-812. doi:10.1080/026404104 10001716689

Lindwall, M., Aşçi, F. H., Palmeira, A., Fox, K. R., \& Hagger, M. S. (2011). The importance of importance in the physical self: support for the theoretically appealing but empirically elusive model of James. Journal of Personality, 79(2), 30334. doi:10.1111/j.1467-6494.2010.00678.x

Mann, M., Hosman, C. M. H., Schaalma, H. P., \& de Vries, N. K. (2004). Self-esteem in a broad-spectrum approach for mental health promotion. Health Education Research, 19(4), 357-72. doi:10.1093/her/cyg041

Manthorpe, J., \& Iliffe, S. (2009). Police and practise in the promotion of mental health and well-being in later life. In M. Cattan (Ed.), Mental health and well-being in later Llfe (First., p. 172). Maidenhead: Open University Press.

Marques, A., Santos, G., Firmini, H., Santos, Z., Vale, L., Abrantes, P., ... Morais, I. (1991). Reações emocionais à doença grave: como lidar. Psiquiatria clínica. Coimbra.

Marsh, H. W., Richards, G., Johnson, S., Roche, L., \& Tremayne, P. (1994). Physical Self-Description Questionnaire: Psychometric properties and a multitrait-multimethod analysis of relations to existing instruments. Journal of Sport and Exercise Psychology, 16, 270-305.

McAuley, E., Mihalko, S. L., \& Bane, S. M. (1997). Exercise and self-esteem in middle-aged adults: Multidimensional relationships and physical fitness and self-efficacy influences. Journal of behavioral medicine, 20(1), 67-83.

Opdenacker, J., Delecluse, C., \& Boen, F. (2009). The longitudinal effects of a lifestyle physical activity intervention and a structured exercise intervention on physical self-perceptions and self-esteem in older adults. Journal of Sport \& Exercise Psychology, 31(6), 743-60.

Razali, N. M., \& Wah, Y. B. (2011). Power comparisons of shapiro-wilk, kolmogorov-smirnov, lilliefors and anderson-darling tests. Journal of Statistical Modeling and Analytics, 2(1), 21-33.

Rosenberg, M. (1965). Society and the adolescent self-image. Princeton, NJ: Princeton University Press.

Schumacker, R. E., \& Lomax, R. G. (2016). A beginner's guide to structural equation modeling (4th Edition). New York: Routledge.

Semerjian, T., \& Stephens, D. (2007). Comparison style, physical self-perceptions, and fitness among older women. Journal of Aging and Physical Activity, 15, 219-235.

Silber, E., \& Tippett, J. S. (1965). Self-esteem: Clinical assessment and measurement validation monograph supplement 4-V16. Psychological reports, 16(3c), 1017-1071.

Sonstroem, R. J. (1997). The physical self-system: A mediator of exercise and self-esteem. In K.R. Fox (Ed). The physical self: From motivation to well-being (pp. 3-26). Champaign, IL, US: Human Kinetics, xiii, 329 pp.

Sonstroem, R. J., \& Potts, S. A. (1996). Life adjustment correlates of physical self-concepts. Medicine \& Science in Sports \& Exercise, 26, 619-625. 
Sonstroem, R. J., Speliotis, E. D., \& Fava, J. L. (1992). Perceived physical competence in adults: An examination of the Physical Self-Perception Profile. Journal of Sport and Exercise Psychology, 14, 207-221.

Spence, J. C., \& Poon, P. (1997). The effect of physical activity on self-concept: A metaanalysis. Alberta Centre fo WellBeing: Research Update, 4(3), 4.

Tabachnick, B. G., \& Fidell, L. S. (2007). Using multivariate statistics (5th edition). Boston: Pearson. doi:10.1037/022267

Vallerand, R. J. (1989). Vers une méthodologie de validation trans-culturelle de questionnaires psychologiques: Implications pour la recherche en Langue Française. Psychologie Canadienne, 30(4), 662-680.

World Health Organisation. (2014). Mental health: a state of well-being. Retrieved from http://www.who.int/features/ factfiles/mental_health/en/

\section{Corresponding author}

José Pedro Ferreira

Email address |jpferreira@fcdef.uc.pt 